grant from the US National Science Foundation, and received help in developing his commercialization plan from graduating MBA students and interns at the centre. In the past year, InnoGenomics has created five full-time lab-research positions; Sinha anticipates adding several more in the next 12-18 months, including jobs for undergraduates and postdocs in biochemistry and molecular biology.

Another tenant, energy-technology company ReactWell, has taken advantage of the centre's non-profit status, core laboratory facility and access to Tulane's office of technology transfer, says founder Brandon Iglesias. In April, Iglesias won \$20,000 in start-up capital from the Tulane Business Plan Competition and the Domain Companies New Orleans Entrepreneur Challenge, to develop ways to use underground geothermal reactors to create synthetic crude oil from algal biomass. "It's quite scary to be in a start-up because the risk is pretty high," he says. "But I can't think of a more important issue to be working on than energy security." Iglesias says that New Orleans' location on the major waterway of the Mississippi River, close to the oil and gas industry and aquaculture in the Gulf of Mexico, gave him ready access to experts in his field.

The city still faces formidable challenges. More start-up capital is needed for new companies, and researchers at local universities aren't necessarily trained to meet businesses' needs.

"We have these institutions in place to help with training, but we just need to make sure that the programming they're providing matches the needs of the companies that we're putting together," says Miscenich. He adds that, for the city to succeed as a biohub, it must be able to retain talent. Louisiana must maintain its tax incentives and business infrastructure, and encourage an influx of established pharmaceutical firms and CROs to buoy the young companies and bring new jobs to the area.

"We need to come up with a business rationale to keep these companies in New Orleans," says Miscenich. "It's not just going to be the good food or the music; it's going to be because it makes economic sense to the company." -

Amanda Mascarelli is a freelance science writer based in Denver, Colorado.

\section{CLARIFICATION}

In the Turning Point on Mayim Bialik (Nature 483, 669; 2012) the quote about Stephen Hawking attributed to Kaley Cuoco was said by her character Penny during the show.

COLUMN

\title{
Piled too high
}

\section{A passion for science is admirable, but can have unwanted outcomes, argues Mariano A. Loza-Coll.}

A $\mathrm{n}$ independent film about the pursuit of a science $\mathrm{PhD}$ became a hit last year at least among the fledgling scientists that it represents. Thousands flocked to see The PhD Movie, based on the hugely popular comic strip Piled Higher and Deeper by Jorge Cham, a former mechanical engineer, at hundreds of on-campus screenings in several countries. Not bad for a film produced, directed and acted in by graduate students and researchers at the California Institute of Technology in Pasadena, and funded on a shoe-string budget.

Why the popularity? The film puts the plight of the $\mathrm{PhD}$ student on the big screen, giving student audiences a chance to laugh at themselves in recognition of the years of schooling, hard work and frustration that they are undertaking.

But I would argue that there is another reason: the film tackles some of the negative aspects of pursuing a $\mathrm{PhD}$ and a science career. At its climax, The PhD Movie raises a question that crosses many students' minds: why bother? The answer it provides resonates with the audience: "Everybody is here because they want to be here... You have to embrace the things you're passionate about."

Yet the passion that drives many scientists to investigate the natural and physical world can also get them into trouble. It compels them to push the boundaries of science, but not always with healthful long-term consequences.

Hard work and a stubborn can-do attitude are admirable and rewarding. We put hours, days and months into experiments that don't work, because we're passionate about the exhilarating moments when they do. But the tradeoffs and downsides are many. The romantic ideal of the scientist as an independent academic investigator uncovering knowledge can convince some very smart people to accept mediocre pay and delays in starting a family, settling down, buying a house and planning for retirement - with no guarantees that these sacrifices are worthwhile. That is the drama so nicely portrayed in The PhD Movie.

The film could be seen as a warning, showing budding researchers that they need to be realistic about their career expectations. But I see it as much more. It is a wake-up call for scientists and non-scientists alike. After all, it is not scientists, but the rest of society that may suffer most if scientists end up burning out. To ensure that scientists can cure diseases, feed the hungry and prevent environmental catastrophes, we should

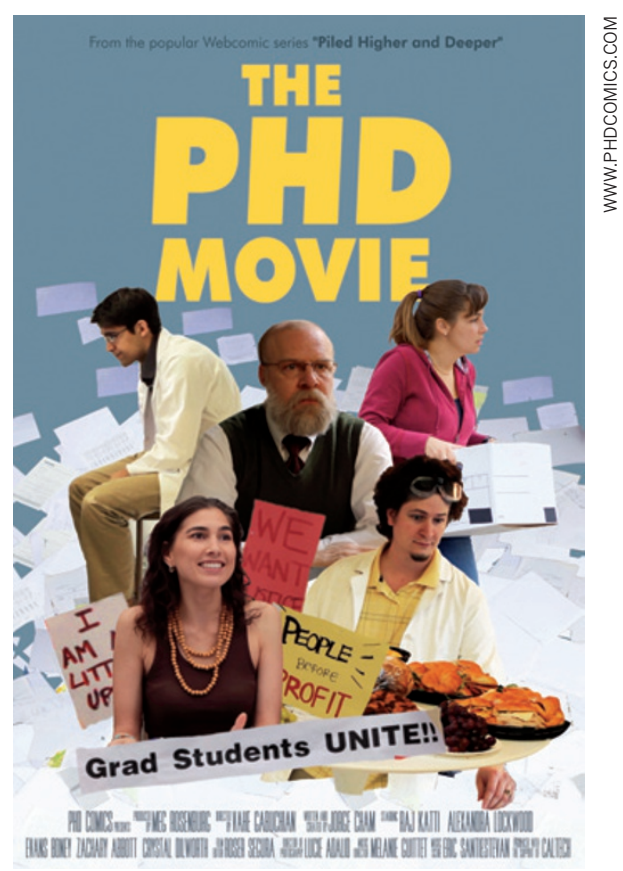

select them on the basis of their intelligence, effectiveness and focus, not their personal sacrifices, obsession and stamina.

Why, then, isn't society at large demanding changes? I suspect that most people just don't know or understand what it takes to advance as a scientist. In the interests of science outreach, The PhD Movie and similar films should be distributed more widely to society at large (it can be viewed for a small fee at www.phdmovie.com).

We can use such films to start a conversation about how to nurture the practitioners and purveyors of science. With a good dose of sarcasm, The PhD Movie shows how graduate students spend much of their day secondguessing why they would spend another minute doing science. Another film, the 2009 documentary Naturally Obsessed (www. naturallyobsessed.com), shows how capable, aspiring science graduate students become 'drop-outs' and 'sell-outs' for reasons that have nothing to do with intelligence and drive.

Scientists complain about how we are portrayed in popular culture. Maybe it is time to start sharing who we are, and what we do.

Mariano A. Loza-Coll is a postdoc in genetics at the Salk Institute for Biological Studies in La Jolla, California. 